\title{
Synthesis of biodiesel by In-situ transesterification of Karanja oil
}

\author{
S. V. A. R. Sastry ${ }^{\text {** }}$ and C. V. R. Murthy ${ }^{2}$ \\ ${ }^{1}$ Research Scholar, J.N.T.U.K, Kakinada, Andhra Pradesh, India, \& Senior Asst. Professor, MVGRCOE, \\ Vizianagaram, Andhra Pradesh, India \\ ${ }^{2}$ Professor, Department of Chemical Engineering, AUCE \& Principal, A.U. College of Engineering, \\ Visakhapatnam, India
}

\begin{abstract}
In the present study, biodiesel has been prepared from Karanja seeds which have been dried, dehulled and powdered. In-situ transesterification is done using the seed powder at a temperature of $50{ }^{\circ} \mathrm{C}$. The molar ratio of methanol to oil $(8: 1,7: 1,6: 1,5: 1,4: 1,3: 1)$, $\mathrm{KOH}$ concentration $(2.0 \mathrm{wt} \%, 1.5 \mathrm{wt} \%, 1.0 \mathrm{wt} \%, 0.5 \mathrm{wt} \%, 0.25 \mathrm{wt} \%$ ) and time (60 min, $45 \mathrm{~min}, 30 \mathrm{~min}, 15 \mathrm{~min}$ and $10 \mathrm{~min}$ ) were studied. In this method glycerol (which is obtained as a by-product in conventional method of biodiesel) is adsorbed onto the oilseeds. Hence the glycerol removal step is eliminated. To better evaluate the conversion of the vegetable oils into the respective methyl esters, the transesterification reactions were monitored by Thin Layer Chromatography (TLC). In this paper the feasibility of biodiesel formation is tested and is hence proven that biodiesel can be formed by this process.
\end{abstract}

Keywords: Biodiesel; Glycerol; Insitu; Karanja; Transesterification

\section{Introduction}

Biodiesel can be synthesized using a transesterification reaction to obtain monoalkyl esters of long-chain fatty acids. (Fig. 1)

Under Indian conditions only non-edible oils can be used as biodiesel which are produced in appreciable quantity and can be grown in large scale on non-cropped marginal lands and waste lands. Non-edible oils like jatropa, karanja and mahua contain $30 \%$ or more oil in their seed, fruit or nut (Boocock et al.; 1998; Sastry and Murthy, 2013; Vivek and Gupta, 2004; Zhou et al., 2003). The oil content extracted ranges between 30.0 to 33\% (Sastry and Murthy, 2012; Sharma and Singh, 2007; Karmee and Chadha, 2005). Transesterification or alcoholysis is the displacement of alcohol from an ester by another in a process similar to hydrolysis, except then alcohol

Figures

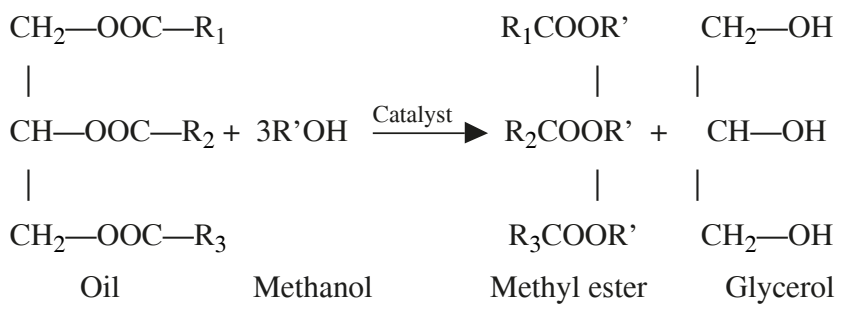

Fig. 1. Transesterification reaction is used instead of water. This process has been widely used to reduce the high viscosity of triglycerides. The transesterification reaction is represented by the general equation (Sastry and Murthy, 2011; Sharma and Singh, 2007, Karmee and Chadha, 2005, Lu et al., 2009)." (Fig. 1)

"Freedman et al., 1984 studied the effect of molar ratio of methanol to oil and effect of changes in concentrations of tri-, di- and monoglyceride on ester yield. They obtained the results for methanolysis of sunflower oil, in which the molar ratio varied from $6: 1$ to $1: 1$ and concluded that $98 \%$ conversion to ester was obtained at a molar ratio of 6.1."

"In the present work the concept of "In-situ transesterification" is used which is a relatively new approach for synthesizing biodiesel. "In-situ" means in place and "transesterification" (also called as alcoholysis) is the reaction of a fat or oil with an alcohol in the presence of catalyst to form esters and glycerol. In the conventional method, oil is extracted from the oil seeds and is then subjected to transesterification. But in in-situ transesterfication the oil seed is directly used (Watanabe et al., 2000). The present study is mainly a qualitative analysis and the main aim of this work is to check the feasibility of the process. In situ transesterification differs from the conventional reaction in that the oil-bearing material contacts

\footnotetext{
*Corresponding author: E-mail: svarsastry@yahoo.com
} 
with acidified or alkalized alcohol directly instead of reacting with pre-extracted oil and alcohol. That is, extraction and transesterification takes place simultaneously, the alcohol acts as an extraction solvent and an esterification reagent (Gerhard, 2005). Several authors (Han et al., 2005; Georgogianni et al., 2008: Pena et al., 2009) have discussed the problem of the mass transfer limitations in transesterification reactions due to low oil solubility in alcohol phase; this problem slows down the reaction resulting in low ester yield."

\section{Materials and methods}

\section{Karanja seeds}

The feed material used in this process for the production of biodiesel is dried, de-hulled and crushed karanja seeds. The seeds were ground and to reduce the particle size a vibrator sieve-shaker was employed to separate the seeds into five different sizes (2-4 mm, 1-2 mm, 1-0.71 mm, 0.71-0.5 mm and $<0.5 \mathrm{~mm}$ ). Karanja is often known by the synonym Pongamia pinnata, which is also one of the few nitrogen fixing trees (NFTS) which produces seeds containing 30-33\% oil. Karanja oil is reported to contain furanoflavones, furanoflavonols, chromenoflavones, flavones and furanodiketones which make the oil non-edible (Vivek and Gupta, 2004; Boocock 1998; Zhou 2003; Karmee and Chadha, 2005; Qian et al. 2008). The molecular composition of karanja oil is shown in Table I.

\section{Table I. Molecular composition of karanja oil}

Fatty Acid

Molecular formula

Palmitic acid

$\mathrm{C}_{16} \mathrm{H}_{32} \mathrm{O}_{2}$

Stearic acid

$\mathrm{C}_{18} \mathrm{H}_{36} \mathrm{O}_{2}$

Oleic acid

$\mathrm{C}_{18} \mathrm{H}_{34} \mathrm{O}_{2}$

Linoleic acid

$\mathrm{C}_{18} \mathrm{H}_{32} \mathrm{O}_{2}$

Eicosanoic acid

$\mathrm{C}_{20} \mathrm{H}_{40} \mathrm{O}_{2}$

$\mathrm{C}_{22} \mathrm{H}_{44} \mathrm{O}_{2}$

Dosocasnoic acid

$$
\mathrm{C}_{24} \mathrm{H}_{48} \mathrm{O}
$$

\section{Methanol}

Methanol is preferred over others due to its low cost (Kumar et al., 2003).

\section{Potassium hydroxide ( $\mathrm{KOH})$}

To enhance the transesterification reaction, base catalyst is the most commonly used since it reaches the completion faster than that of acid catalyst (Ramadhas et al., 2005). $\mathrm{KOH}$ is the common catalyst employed during alkaline transesterification at industrial level application (Ma and Hanna, 1999). Apart from that the soap formation is also very less with $\mathrm{KOH}$ in comparison to Sodium hydroxide $(\mathrm{NaOH})$ (Lu et al., 2009).

\section{Experimental set-up}

The experimental setup consists of mantle heater, round bottom flask (material of Construction: borosilicate glass,

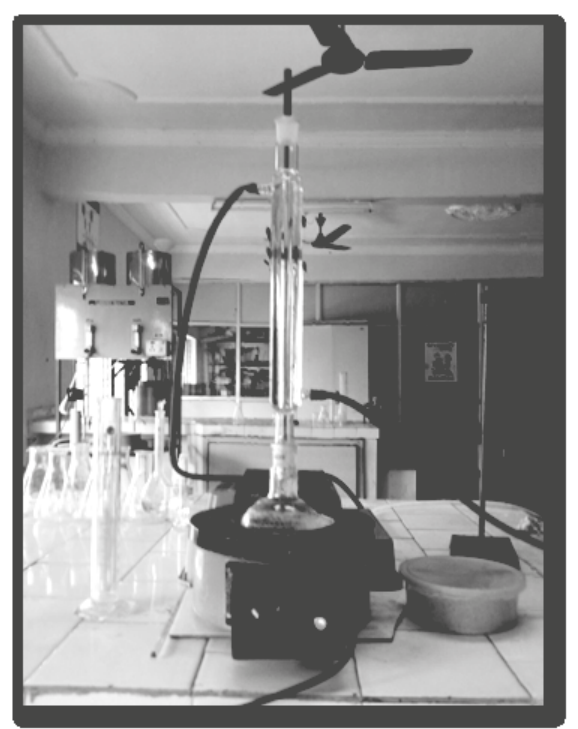

Fig.2. Experimental Setup

$\begin{array}{cl}\text { Percentage } & \text { Structure } \\ 21.65 & \mathrm{CH}_{3}\left(\mathrm{CH}_{2}\right)_{14} \mathrm{COOH} \\ 7.5 & \mathrm{CH}_{3}\left(\mathrm{CH}_{2}\right)_{16} \mathrm{COOH} \\ 51.59 & \mathrm{CH}_{3}\left(\mathrm{CH}_{2}\right)_{14}(\mathrm{CH}=\mathrm{CH}) \mathrm{COOH} \\ 6.64 & \mathrm{CH}_{3}\left(\mathrm{CH}_{2}\right)_{12}(\mathrm{CH}=\mathrm{CH})_{2} \mathrm{COOH} \\ 1.35 & \mathrm{CH}_{3}\left(\mathrm{CH}_{2}\right)_{18} \mathrm{COOH} \\ 4.45 & \mathrm{CH}_{3}\left(\mathrm{CH}_{2}\right)_{20} \mathrm{COOH} \\ 1.09 & \mathrm{CH}_{3}\left(\mathrm{CH}_{2}\right)_{22} \mathrm{COOH}\end{array}$

capacity: $500 \mathrm{ml}$ ), reflux condenser and simple distillation equipment for recovery of methanol. Apart from these, funnel, filter paper, conical flasks, beakers, specific gravity bottle are required for experimental usage. (Fig. 2)

\section{Experimental procedure}

- The karanja seeds are dried, de-hulled and crushed. 20 gm of the crushed seeds powder is weighed. $\mathrm{KOH}$ (in the ratio $2 \mathrm{wt} \%$ to $0.25 \mathrm{wt} \%$ of seed powder) is dissolved in methanol by vigorous stirring and methoxide ion solution is formed. Seed powder (in the 
ratio $8: 1$ to $2: 1$ of methanol) is taken in a round bottom flask. The mixture is vigorously heated up to the temperature of $50{ }^{\circ} \mathrm{C}$, using a mantle heater for different periods of time $(10 \mathrm{~min}$ to $60 \mathrm{~min})$. After the specified time period, the mixture is cooled and filtered using a filter paper to get the solution. The liquid obtained is a homogenous mixture of biodiesel, glycerine and methanol. The liquid mixture is distilled to remove the methanol. Biodiesel is collected as the residue. Methanol which is obtained as a distillate can be reused. The procedure is repeated for different alcohol to seed ratios, catalyst percentages and reaction times.

- The biodiesel produced is qualitatively analysed using Thin Layer Chromatographic (TLC) technique (Fukuda et al., 2001).

\section{Operating parameters}

Temperature inside the reactor $\left(50^{\circ} \mathrm{C}\right)$, Pressure inside the reactor $(1 \mathrm{~atm})$, methanol-seed powder molar ratio $(8: 1,7: 1$, $6: 1,5: 1,4: 1,3: 1,2: 1)$, catalyst concentration $(2 \%, 1.5 \%, 1 \%$, $0.5 \%, 0.25 \% \mathrm{wt})$, reaction time (60 $\mathrm{min}, 45 \mathrm{~min}, 30 \mathrm{~min}, 15$ $\min , 10 \mathrm{~min})$.

\section{Analysis of biodiesel}

Thin layer chromatography is used for the qualitative analysis of biodiesel. Thin layer chromatography is performed on aluminium foil, which is coated with a thin layer of adsorbent material (silica gel). This layer of adsorbent is known as the stationary phase.

After the sample has been applied on the plate, a solvent or solvent mixture (known as the mobile phase) is drawn up the plate via capillary action. Because different analytes ascend the plate at different rates, separation is achieved (Fukuda et al. 2001).

Thin layer chromatography can be used to monitor the progress of a reaction, identify compounds present in a given substance and determine the purity of a substance.

\section{Apparatus required for the TLC analysis}

Thin-layer chromatography (TLC) aluminum plates $(20 \mathrm{~cm}$ $20 \mathrm{~cm} \_250 \mu \mathrm{m}$, merck). Qualitative filter paper (grade no. 2 , $0.26 \mathrm{~mm}$ thickness, $80 \%$ collection efficiency), iodine chamber, developing chamber, TLC plate, micro capillary tubes for spotting, UV lamp (Fukuda et al. 2001).

\section{TLC analysis procedure}

A small spot of solution containing the sample is applied to a plate, about $1.5 \mathrm{~cm}$ from the bottom edge. The solvent is allowed to completely evaporate, otherwise a very poor or no separation will be achieved. If a non-volatile solvent is used, the plate needs to be dried in a vacuum chamber. A small amount of an appropriate solvent (elutant) is poured in to a glass beaker or any other suitable transparent container (separation chamber) up to a depth of less than $1 \mathrm{~cm}$. A strip of filter paper is put into the chamber, so that its bottom touches the solvent, and the paper lies on the chamber wall and reaches almost to the top of the container. The container is closed with a cover glass or any other lid and is left for a few minutes to let the solvent vapours ascend the filter paper and saturate the air in the chamber. (Failure to saturate the chamber will result in poor separation and non-reproducible results). The TLC plate is then placed in the chamber so that the spots of the sample do not touch the surface of the elutant in the chamber, and the lid is closed. The solvent moves up the plate by capillary action, meets the sample mixture and carries it up the plate (elutes the sample). When the solvent front reaches no higher than the top of the filter paper in the chamber, the plate should be removed (continuation of the elution will give a misleading result) and dried.

Separation of compounds is based on the competition of the solute and the mobile phase for binding places on the stationary phase. As the chemicals being separated may be colourless, Iodine vapours were used as a general unspecific colour reagent.

Once visible, the $\mathrm{Rf}$ value, or retention factor, of each spot was determined by dividing the distance travelled by the product by the total distance travelled by the solvent (the solvent front). These values depend on the solvent used, and the type of TLC plate, and are not physical constants (Fukuda et al. 2001).

The $\mathrm{R}_{\mathrm{f}}$ value was calculated using the following formulae:

\section{Rf = distance travelled by component/distance travelled by solvent}

Test procedures for different properties of biodiesel

\section{Density}

Take an empty specific gravity bottle and weigh it accurately. Fill the specific gravity bottle with biodiesel upto the mark. Weigh it again and note the readings.

Density $=$ weight in grams / volume of specific gravity bottle Viscosity

Clean the oil cup and place the ball valve in position and fill the oil cup to the pointer level with filtered sample. Fill the 
heating bath with water up to the level. Place the $50 \mathrm{ml}$ gravity bottle just below the jet of oil for $50 \mathrm{ml}$ collection of given oil in seconds at room temperature. Replace the sample up to the mark. Heat the oil sample through water bath with the help of immersion heater. After attaining a steady temperature by continuous stirring determine time taken for $50 \mathrm{ml}$ of oil collection in seconds. Repeat the above procedure for given temperature and report the values. Calculate the density of oil with the help of analytical balance and determine absolute viscosity.

Kinematic viscosity in stokes $=0.00264 \mathrm{t}-(1.79 / \mathrm{t})$

Absolute viscosity $=$ kinematic viscosity $*$ Density

\section{Flash point \& Fire point}

Fill the oil cup of Pensky Marten's apparatus with the test oil up to the mark. Fix the lids on the top through which are inserted a thermometer and a stirrer. Ensure that the flame exposure device is fixed on the top. Light the test flame and adjust it to about $4 \mathrm{~mm}$ in diameter. Heat apparatus as temperature of oil increases by 5 to 60 per min. as stirrer is continuously rotated. At every $10^{\circ} \mathrm{C}$ rise of temp. Introduce test flame into the oil vapor. This is done by operating the shutter. On moving knob of shutter, test flame is lowered in oil vapors through opening. When test flame causes a distinct flame in interior cup, note temperature which represents the flash point. Further heat the oil at the rate of $10^{\circ} \mathrm{C}$ per min. and continue applying the test flame as before. The temperature at which the vapors of the oil give a clear and distinct blue flash for five seconds is recorded as the fire point of the oil.

\section{Pour point}

The specimen is cooled inside a cooling bath to allow the formation of paraffin wax crystals. At about $9{ }^{\circ} \mathrm{C}$ above the expected pour point, and for every subsequent $3{ }^{\circ} \mathrm{C}$, the test jar is removed and tilted to check for surface movement. When the specimen does not flow when tilted, the jar is held horizontally for $5 \mathrm{sec}$. If it does not flow, $3{ }^{\circ} \mathrm{C}$ is added to the corresponding temperature and the result is the pour point temperature.

\section{Cloud point}

The test sample is first poured into a test jar to a level approximately half full. A cork carrying the test thermometer is used to close the jar. The thermometer bulb is positioned to rest at the bottom of the jar. The entire test subject is then placed in a constant temperature cooling bath on top of a gasket to prevent excessive cooling. At every $1{ }^{\circ} \mathrm{C}$, the sample is taken out and inspected for cloud then quickly replaced.

\section{Cetane number}

It is found using the Ignition Quality Tester (IQT). Fuel is injected into a constant volume combustion chamber at approximately $575^{\circ} \mathrm{C}$ and 310 psi. The time between the start of injection and the recovery of the combustion chamber pressure to $310 \mathrm{psi}$ is defined as the ignition delay. This measured ignition delay is then used to calculate the Cetane number of the fuel. The fuel's Cetane number is then calculated using an empirical inverse relationship to ignition delay.

\section{Iodine number}

Dissolve 13.2 gms of iodine in 1 liter of glacial acetic acid. Add about $3 \mathrm{ml}$ of bromine (carefully) and mix well. Prepare a solution of sodium thiosulphate by dissolving $13.2 \mathrm{gms}$ in $1000 \mathrm{ml}$ of water. Standardize this. Weigh out $1 \mathrm{~g}$ of oil into a flask and dissolve in $10 \mathrm{ml}$ chloroform. Add $80 \mathrm{ml}$ of iodine solution and allow standing with occasional shaking for 30 minutes. Add $10 \mathrm{ml}$ of $15 \% \mathrm{KI}$ solution, shake well and then add $100 \mathrm{ml}$ water. Titrate against the thiosulphate till the yellow color just disappears, add starch and titrate again till the blue color is bleached. Repeat with a blank with no oil. Subtracting this blank, calculate the thiosulphate equivalent of iodine absorbed by fat. Calculate the grams of iodine absorbed by $100 \mathrm{~g}$ of fat. This is called the iodine value. Compare the iodine values of different oils and comment on their unsaturation.

Iodine number of sample $=(x * 12.7 * 0.1) /($ weight of the fat sample used for analysis)

$$
\mathrm{X}=\text { Blank }- \text { Test }
$$

\section{Acid number}

Weigh accurately the empty beaker into which the biodiesel sample is to be transferred. Transfer 5 drops (about 1gms) of biodiesel sample into the beaker and take the final weight of the beaker, and find the exact weight of the biodiesel sample transferred into the beaker. The difference gives you the weight of the biodiesel sample. Add $50 \mathrm{ml}$ of suitable titration solvent usually methanol with a measuring cylinder. Shake vigorously to dissolve the biodiesel sample to maximum extent. Transfer the contents into a $250 \mathrm{ml}$ conical flask and heat the reaction mixture to boiling on a water bath. Add 3-4 drops of Phenolphthalein indicator and titrate against the $0.1 \mathrm{~N} \mathrm{KOH}$ solution until a sharp color change from colorless 
to pale pink is observed. Record the volume of $\mathrm{KOH}$ rundown as ' $\mathrm{X}$ ' $\mathrm{ml}$.

\section{Saponification number}

Weigh $1 \mathrm{~g}$ of oil in a beaker and dissolve in about $3 \mathrm{ml}$ of the oil solvent (ethanol /ether mixture). Quantitatively transfer the contents of the beaker three times with a further $7 \mathrm{ml}$ of the solvent. Add $25 \mathrm{ml}$ of $0.5 \mathrm{~N}$ alcoholic $\mathrm{KOH}$ and mix well, attach this to a reflux condenser. Set up another reflux condenser as the blank with all other reagents present except the fat. Place both the flasks in a boiling water bath for 30 minutes. Cool the flasks to room temperature. Now add phenolphthalein indicator to both the flasks and titrate with $0.5 \mathrm{~N} \mathrm{HCl}$. Note down the endpoint of blank and test. The difference between the blank and test reading gives the number of milliliters of $0.5 \mathrm{~N} \mathrm{KOH}$ required to saponify $1 \mathrm{~g}$ of fat.

Calculate the saponification value using the formula :

Saponification value $=($ blank - sample titration $) *($ reagent factor)*

(Concentration conversion coefficient)/(weight of fat)

\section{Results and discussion}

Experiments have been done by varying the different parameters like reaction time, catalyst concentration and methanol to oil seed ratio. Different conversions of the product have been obtained for each case. Glycerol formed as a by-product gets adsorbed onto the crushed seed particles and is removed along with the sludge after filtration.

The experiments show the feasibility of the reaction. The optimum feasible conditions for synthesizing biodiesel from karanja oil seed are taken to be $30 \mathrm{~min}, 6: 1$ and $1.0 \mathrm{wt} \%$.

\section{Effect of methanol to oil seed ratio on conversion}

The effect of methanol to oil seed ratio has been studied, at different methanol to oil seed ratios $(3: 1,4: 1,5: 1,6: 1,7: 1$, $8: 1$ ). The conversion of karanja oil seed powder to biodiesel increases with the reactant ratio (moles of methanol: moles of oil seed). This can be seen from the graph of reactant ratio vs conversion. The graph shows that a high conversion of 62.5 $\%$ is reached at the methanol-oil seed ratio of $6: 1,7: 1$ and $8: 1$. The initial conversion is high uptill 30 minutes for $7: 1$ and $8: 1$ molar ratios. (Fig. 3)

This can be attributed to the fact that more amount of methoxide solution is available for the oil seed powder to react. But as time increases, the conversion is observed to reach $62.5 \%$, although it is not increasing beyond this value. The reasons for low conversion are (Vivek and Gupta, 2004):

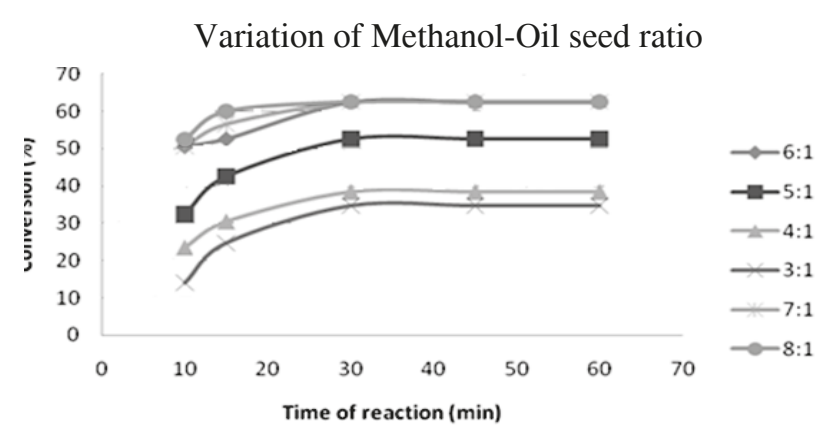

Fig. 3. Variation of methanol-oil seed ratio

(i) Oil present in the oil seed powder is only upto $30 \%$, leading to lesser conversion.

(ii) Side reaction of saponification taking place alongwith transesterification, which also limits the conversion.

\section{Effect of $\mathrm{KOH}$ concentration on conversion}

From the graph, it is clear that the maximum conversion of $62.5 \%$ is reached at the catalyst concentration of 1.0. wt \%. Although similar conversion is obtained at the catalyst concentration of $1.5 \mathrm{wt} \%$. It is also observed that at the catalyst concentartion of $2.0 \mathrm{wt} \%$, the conversion has dropped. (Fig. 4)

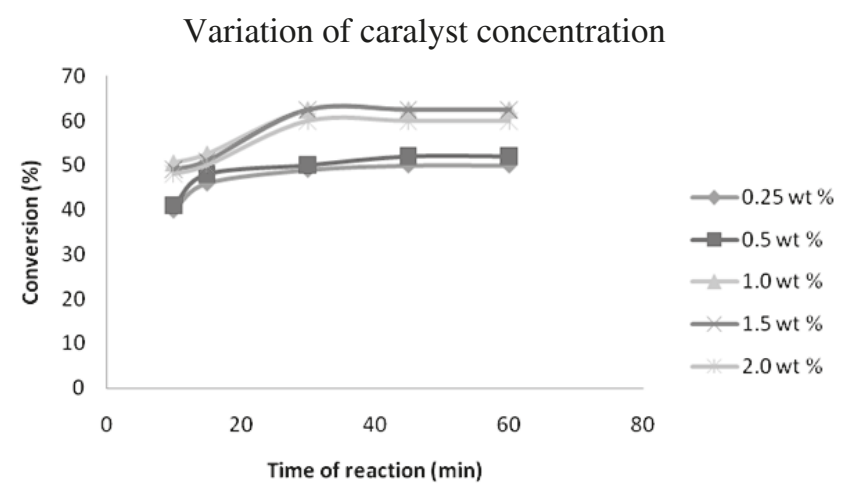

Fig. 4. Variation of catalyst concentration

This may be attributed to the possible soap formation as a side reaction, which has led to the decrease in the biodiesel formation. Considering these factors, the optimal catalyst concentration is determined as $1.0 \mathrm{wt} \%$. 


\section{TLC analysis}

The retention factor is calculated from the TLC sheets and the conversion of Karanja seed powder into biodiesel for various reaction times, methanol-oil seed ratios and catalyst concentrations are obtained. From the TLC test analysis it was observed that the $\mathrm{Rf}$ is 0.8 (highest) for the optimum feasible conditions obtained at $30 \mathrm{~min}, 6: 1$ and $1.0 \mathrm{wt} \%$ and the conversion at these conditions was found to be $62.5 \%$ as shown in Fig. 5, Table II, Table III, Table IV.

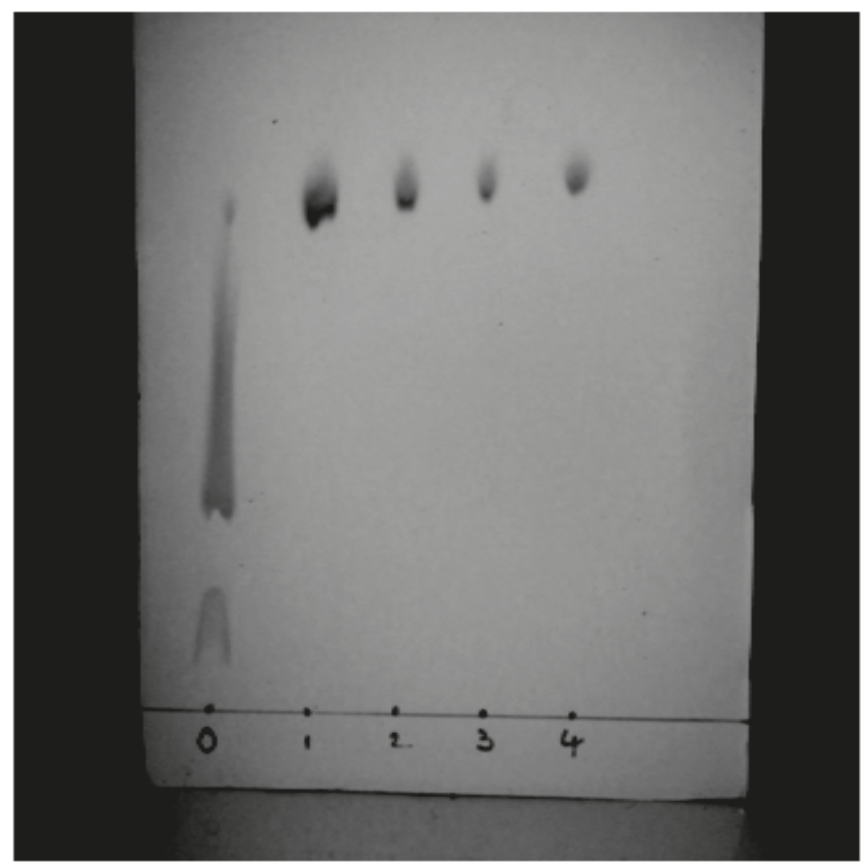

Fig.5. Sample TLC sheet of the product

Table II. Retention factor values for the samples at different molar ratios

$\begin{array}{lllllll}\text { Time of reaction }(\mathrm{min}) & 60 & 60 & 60 & 60 & 60 & 60 \\ \text { Methanol-oil seed ratio } & 7: 1 & 8: 1 & 6: 1 & 5: 1 & 4: 1 & 3: 1 \\ \text { Catalyst concentration }(\mathrm{Wt} \%) & 1.0 & 1.0 & 1.0 & 1.0 & 1.0 & 1.0 \\ \text { Retention factor }\left(\mathrm{R}_{\mathrm{f}}\right) & 0.8 & 0.8 & 0.8 & 0.74 & 0.72 & 0.64\end{array}$

Table III. Retention factor values for the samples at different catalyst concentrations

Time of reaction $(\mathrm{min})$

$\begin{array}{lllll}60 & 60 & 60 & 60 & 60\end{array}$

Methanol-oil seed ratio

6:1 $6: 1 \quad 6: 1 \quad 6: 1 \quad 6: 1$

Catalyst concentration (wt \%) $2.0 \quad 1.5 \quad 1.0 \quad 0.5 \quad 0.25$

Retention factor $\left(\mathrm{R}_{\mathrm{f}}\right)$

$\begin{array}{lllll}0.8 & 0.8 & 0.8 & 0.74 & 0.64\end{array}$
Table IV. Retention factor values for the samples at different times

Time of reaction $(\mathrm{min})$

$\begin{array}{lllll}60 & 45 & 30 & 15 & 10\end{array}$

Methanol-oil seed ratio

6:1 6:1 6:1 6:1 6:1

Catalyst concentration (wt \%) $1.01 .01 .0 \quad 1.0 \quad 1.0$

Retention factor $(\mathrm{Rf})$

0.80 .80 .80 .720 .7

IR spectrum of biodiesel

PerkinElmer's EcoAnalytix Biodiesel IR FAME Analyzer comprises a Spectrum $^{\text {TM }} 100$ FT-IR spectrometer with the appropriate ATR or transmission accessory, and Spectrum Express $^{\mathrm{TM}}$ software with a dedicated FAME analysis module that can be configured for either ASTM D7371 or EN 14078. The ASTM version of the analyzer supports either a $\mathrm{ZnSe}$ horizontal ATR (HATR) or, for much greater ruggedness and improved cleanability, a Universal ATR (UATR) with a 9-bounce diamond ATR element.

Biodiesel has a strong infrared absorption at around 1743 cm-1 (due to the ester carbonyl bond) as shown in Fig. 6.

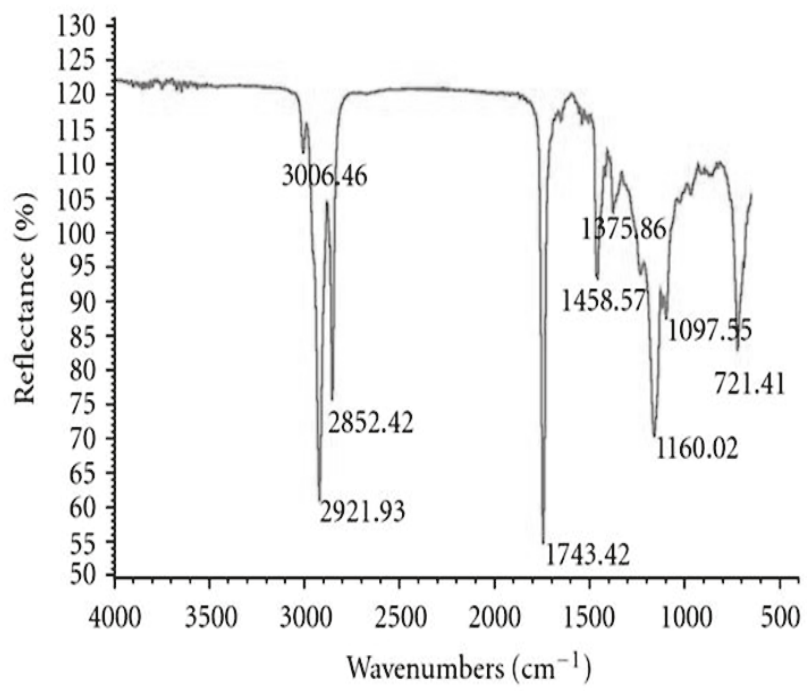

Comparison of the properties of biodiesel produced with diesel

The important fuel properties are tested as per the ASTM standards and compared with that of Diesel fuel. It has been found that the values are comparable as shown in Table V. 
Table V. Comparison of the properties of Diesel, Biodiesel \& Oil

\begin{tabular}{lccc}
\hline Property & Diesel & Biodiesel & Oil \\
\hline Density $\left(\right.$ at $30{ }^{\circ} \mathrm{C}$ ) $\mathrm{g} / \mathrm{cm} 3$ & 0.82 & 0.83 & 0.88 \\
Viscosity $\left(\right.$ at $40{ }^{\circ} \mathrm{C}$ ) stokes & 0.03 & 0.038 & 0.306 \\
Flash point ${ }^{\circ} \mathrm{C}$ & 71 & 130 & 212 \\
Fire point ${ }^{\circ} \mathrm{C}$ & 80 & 140 & 222 \\
Pour point ${ }^{\circ} \mathrm{C}$ & -9 & -6 & -3 \\
Cloud point ${ }^{\circ} \mathrm{C}$ & -6 & -3 & 3 \\
Cetane number & 45 & 52 & 40 \\
Iodine number g/100g & 6 & 48 & 98 \\
Acid number, mg KOH/g & 0.07 & 0.25 & 8 \\
Saponification value & --- & 14.1 & 141 \\
& & &
\end{tabular}

\section{Conclusions}

1. This process is advantageous in the sense that it eliminates the glycerol recovery step (in the conventional trans-esterification process) as the glycerol formed gets adsorbed in the seed powder after the reaction is over.

2. The optimum feasible conditions for synthesizing biodiesel from karanja oil seed powder are obtained from the experiment and conversion was found.

3. The results show that the insitu transesterification reaction of karanja oil seed powder depends on catalyst concentration and ratio of methanol to karanja oil seed powder. The conversion obtained was about $62.5 \%$, even after 60 minutes. The optimum time of reaction is found to be 30 minutes. Optimum catalyst is $1.0 \mathrm{wt} \%$. The optimum methanol to oil ratio is $6: 1$.

\section{References}

Boocock DGB, Konar SK, Mao V and Lee C (1998), Buligan $\mathrm{S}$, Fast formation of high-purity methyl esters from vegetable oils, JAOCS. 75: 1167-1172.

Georgogianni KG, Kontominas MG, Pomonis PJ, Avlonitis D and Gergis V (2008), Conventional and in situ transesterification of sunflower seed oil for the production of biodiesel, Fuel Process Technol. 89: 503-509.
Gerhard K (2005), The Biodiesel Handbook. (AOCS Press) 2005, ISBN 978-1893997790.

Han H, Cao W and Zhang J, Preparation of biodiesel from soybean oil using supercritical methanol and $\mathrm{CO} 2$ as co-solvent (2005), Process Biochem. 40: 3148-3151.

Karmee SK and Chadha A (2005), Preparation of biodiesel from crude oil of Karanja pinnata, Bioresour Technol. 96: $1425-1429$.

Lu H, Liu Y, Zhou H, Yang Y, Chen M and Liang B (2009), Production of biodiesel from Jatropha curcas L. oil, Computers and Chemical Engineering. 33: 1091-1096.

Ma F and Hanna MA (1999), Biodiesel production: a review, Bioresour Technol. 70: 1-15.

Fukuda H, Kondo A and Noda H (2001), Biodiesel fuel production by transesterification of oils, J Biosci Bioeng. 92: 405-416.

Pena R, Romero R, Martínez S, Ramos M, Martínez A and Natividad R (2009), Transesterification of castor oil: effect of catalyst and co-solvent, Ind Eng Chem Res. 48: 1186-1189.

Qian J, Wang F, Liu S and Yun Z (2008), In situ alkaline transesterification of cottonseed oil for production of biodiesel and nontoxic cottonseed meal, Bioresour Technol. 99: 9009-9012.

Ramadhas AS, Jayaraj S and Muraleedharan C (2005), Biodiesel production from high FFA rubber seed oil, Fuel. 84: 335-340.

Sastry SVAR and Murthy ChVR (2011), Production of biodiesel from the catalytic transesterification of Jatropha oil, Elixir Chem. Engg. 40: 5136-5137.

Sastry SVAR and Murthy ChVR (2012), Prospects of biodiesel for future energy security, Elixir Chem. Engg. 53: 12029-12034.

Sastry SVAR and Murthy ChVR (2013), Biodiesel production using jatropha oil, pongamia oil and sunflower oil. (Lambert Academic Publishers, Germany) 2013, ISBN 978-3659485275.

Sharma YC and Singh B (2007), Development of biodiesel from Karanja, a tree found in rural India, Fuel. 86: 1740-1742. 
Vivek and Gupta AK (2004), Biodiesel production from karanja oil, J of Sci \& Ind Res. 63: 39-47.

Watanabe Y, Shimada Y, Sugihara A, Noda H, Fukuda H and Tominga Y (2000), Continuous production of biodiesel fuel from vegetable oil using immobilized candida antarctica lipase, J Am Oil Chem Soc.77: 355360 .
Zhou W, Konar SK and Boocock DGB (2003), Ethyl esters from the single-phase base-catalyzed ethanolysis of vegetable oils, JAOCS. 80: 367-371.

Received: 27 November 2013; Revised: 14 October 2014 Accepted: 22 December 2014. 